\section{Das Dr.-Knock-Seminar}

\author{
E. Taverna
}

Kennen Sie den Dreiakter von Jules Romains (1885-1972) «Knock ou le triomphe de la Médecine»? Wenn nicht, dann wäre es allmählich Zeit, von dieser Erfolgsgeschichte zu lernen. Das Theaterstück wurde 1923 mit Louis Jouvet in Paris uraufgeführt und wieder mit ihm in der Hauptrolle 1951 verfilmt. Seither haben bekannte Schauspieler wie Gert Voss und Alfred Rasser den berühmten Kollegen interpretiert. Einmal im Schweizer Film "Dr. Knock», 1974, und zuletzt in der preisgekrönten, bayrischen Dorfsatire von Dominik Graf 1996. Romains Dorfarzt ist ein Vorbild, weil er in einer Zeit, die weder Sozialversicherungen noch Marketingseminare kannte, eine für alle Nachfolgergenerationen erfolgversprechende Praxisstrategie entwickelte. Die Geschichte ist schnell zusammengefasst: Knock übernimmt von seinem Vorgänger eine Landpraxis, die kaum Patienten hat: Les gens d'ici n'auraient pas plus l'idée d'aller chez le médecin pour un rhumatisme, que vous n'iriez chez le curé pour faire pleuvoir. In nur drei Monaten entwickelt der Nachfolger ein Riesengeschäft, das alle Beteiligten zufriedenstellt. Neusprachlich ausgedrückt: die klassische Win-win-Situation des freien Unternehmers.

Knock: Est-ce que ça ne vous grattouille pas davantage, quand vous avez mangé de la tête de veau à la vinaigrette? Tambour: Je n'en mange jamais. Mais il me semble que si j'en mangeais, effectivement, ça me grattouillerait plus.

Knock beherrscht die Kunst der Gesprächsführung. Als erstes macht er die Medien zum Instrument seiner Werbung. Er sichert sich die Dienste des Dorftrommlers und demontiert ganz nebenbei dessen Überzeugung, gesund zu sein. Dann schmeichelt er dem Dorflehrer und gewinnt ihn für eine rigorose öffentliche Hygieneerziehung: [...] car leur tort, ç'est de dormir, dans une sécurité trompeuse dont les réveille trop tard le coup de foudre de la maladie. Dem Apotheker verspricht er mehr Umsatz und dem Hotelbesitzer gefüllte Betten. Mit Gratissprechstunden und unentgeltlichen Besuchen lockt er die Bevölkerung in sein Sprechzimmer und bearbeitet jeden nach seiner Devise: La santé n'est qu'un mot, qu'il n'y aurait aucun inconvénient à rayer de notre vocabulaire. Knock ist ein Meister des Dialogs, bei dem sehr wohl ankommt, was er sagt. Er benötigt keine Kurse zur Kongruenz verbaler und nonverbaler Kommunika- tion, denn die Anatomie seiner Botschaft lautet ganz einfach: Tout homme bien portant est un malade qui s'ignore. Sein Gespür für verborgene Schwächen und heimliche Wünsche schafft die vielzitierte Beziehung, die jenseits aller pathophysiologischen Grundlagen eine stabile Patientenbindung erst ermöglicht.

Vous me donnez un canton peuplé de quelques milliers d'individus neutres, indéterminés. Mon rôle, ç'est de les déterminer, de les amener à l'existence médicale. Je les mets au lit, et je regarde ce qui va pouvoir en sortir [...]

Sie werden einwenden, dass der Kollege ein leichtes Spiel hat, weil er konkurrenzlos eine ignorante Bevölkerung bearbeitet. Doch bedenken Sie, dass er ohne medizinische Callcenters, ohne Assistenz der TVGesundheitsmagazine und ohne staatliche Wellnesskampagnen auskommen muss. Bei diesem Aufklärungsmangel ist nur auf die eigene Initiative Verlass, auf Überzeugungsarbeit, Ressourcenmanagement, Informationskonzepte und gezieltes Einweisermarketing. Knock erfindet ein Recall-System, das alle unablässig in den Dienst der Medizin stellt, er bietet ein flexibles Rundumversorgungspaket, abgestufte Prämien und Vernetzung mit anderen Anbietern. Er motiviert und evaluiert, er sorgt für Sortimentspräsentationen und jede Menge Marktanalysen nach dem Motto "Patienten finden und binden». Knock handelt umsatzorientiert, wie es die Fortbildungsseminare, Qualitätszirkel und Websites zum PatientArzt-Dialog (PAD) von uns fordern. Am Ende überzeugt er sogar seinen altmodisch-skeptischen Vorgänger. Doch mit wem auch immer Sie sich identifizieren, Sie müssen das selber nachlesen. Denn so oder so verhelfen Ihnen Knocks Methoden, sanft modernisiert, zum erstrebten Einkommen und den besseren Benchmarks der nächsten Praxisevaluation, die Sie für kommende Zertifizierungen dringend benötigen. Und noch etwas zum Schluss: Denken Sie an Ihr Burnout. Wenn Louis Jouvet alias Knock zum Fenster tritt, verrät er Ihnen in einer berühmten Szene sein lustvolles Rezept gegen diesen bedauernswerten $\mathrm{Zu}$ stand:

La nuit, ç'est encore plus beau, car il y'a les lumières. Et presque toutes les lumières sont à moi. Les non-malades dorment dans les ténèbres. Ils sont supprimés. Mais les malades ont gardé leur veilleuse ou leur lampe. [...]. Le canton fait place $\dot{a}$ une sorte de firmament dont je suis le créateur continuel.[...]. Songez que dans quelques instants, il va sonner dix heures, que pour tous mes malades, dix heures, c'est la deuxième prise de température rectale, et que dans quelques instants, deux cents cinquante thermomètres vont pénétrer à la fois [...]. 